\title{
Teachers' and students' motivation model as a strategy for open distance learning processes
}

\section{O. ZAIKIN ${ }^{*}$, R. TADEUSIEWICZ², P. RÓŻEWSKI ${ }^{3}$ L. BUSK KOFOED ${ }^{4}$, M. MALINOWSKA $^{5}$, and A. ŻYŁAWSKI ${ }^{1}$}

${ }^{1}$ Warsaw School of Computer Science, 17 Lewartowskiego St., 00-169 Warsaw, Poland

${ }^{2}$ AGH University of Science and Technology, 30 Mickiewicza St., Krakow, Poland

${ }^{3}$ Faculty of Computer Science and Information Systems, West Pomeranian University of Technology in Szczecin, 49 Żołnierska St., 71-210, Szczecin, Poland

${ }^{4}$ Department of Architecture, Design \&Media Technology, Aalborg University Copenhagen, A.C. Meyers Vænge 15, Denmark

${ }^{5}$ Faculty of Management and Economics of Services, University of Szczecin, 8 Cukrowa St., 71-004, Szczecin, Poland

\begin{abstract}
Motivation and social aspects as interaction among teachers and students are essential for a successful learning process in an Open Distance Learning environment, and the goal of this paper is to develop an interactive model to manage motivation between the participants of that process. The article contains the concept of developing a motivation model aimed at supporting activity and cooperation of both the students and the teacher. The structure of the motivation model and formal assumptions are presented. The proposed model constitutes a theoretical formalization of a new situation in which a teacher and the students are obligated to elaborate on a didactic material repository content in accordance with the competence requirements. A mathematical method based on game theory and simulation is suggested. The conditions for applying simulation to the model are analyzed in two simulated cases.
\end{abstract}

Key words: motivation modelling, open distance learning (ODL), task repository, simulation.

\section{Introduction}

During the last 20 years, distance learning has changed considerably, and online teaching and learning have become routine practices at many universities [1]. The technological development, at the same time, has given distance education a new appeal to students as well as teachers. Due to the increasing popularity of distance education, there is a number of definitions connected to the aspects of teaching and learning in online educational systems which need to be clarified [2].

Open Distance Learning (ODL) is often used as a synonym of e-learning and is nowadays considered the most viable means for broadening educational access. The ODL approach supports improving quality of online educations as well as advocating the peer-to-peer collaboration. ODL is giving the learners a greater sense of autonomy and responsibility for their own learning [3]. Moreover, ODL is one of the most popular method to provide opportunities to meet the needs of a growing and increasingly diverse student population [4]. ODL has a number of potential benefits, e.g., the possibility of overcoming the temporal and spatial restrictions of traditional educational settings like space, time, access etc. [1]. Despite all the benefits of ODL, different factors have been identified as crucial to the success of online education. Two of the main factors are motivation and the social aspect (interaction among students and teacher) of learning [5].

\footnotetext{
*e-mail: ozaikin@poczta.wwsi.edu.pl
}

The educational experience is constituted through sustained interaction and communication between and among learners, teachers, and learning objects. In ODL this process can be facilitated through asynchronous and synchronous communication and participation through students' teamwork $[6,7]$.

Motivation is a key factor in learning in case of the face-toface educational contexts [5] as well as in online learning environments [8]. Traditionally online learners have been understood as independent, self-directed and intrinsically motivated [6], but this is not the case. Motivation of the learner is complex, multifaceted and sensitive to situational conditions [8].

The implementation of ODL assumes modification of the traditional organization of learning processes. The special attention is subject to a change in designing the structure and content of the specific educational elements. However, the opportunities of relations between students and the teacher seem to be crucial. The ODL, combined with the new possibilities and strategies of distance learning, provides a basis for active collaboration between teachers and students, between students and students, as well as between students and the university [9].

These new possibilities urge universities to consider the new status of the potential students. This means that, on the one hand, students must be able to achieve knowledge, skills and competences connected to the goals in their curriculum. On the other hand, the universities have to provide the students with an active role in the learning process, to motivate them to work on an independent study program under the supervision of a teacher [10]. 
In this paper we argue that the motivation and social aspects of learning, such as the interaction among teachers and students are essential for a successful learning process in an ODL environment, and our aim is to develop an interactive model to manage motivation related to this process. The paper proposes the concept of developing a motivation model aimed at supporting activity and cooperation of both the students and the teachers in the process of implementing and using ODL systems. The structure of the motivation model and formal assumptions are presented. The proposed model constitutes the theoretical formalization of a new situation in which a teacher and students are obligated to elaborate on a didactic material repository in accordance with the competence requirements. It covers two motivation areas: the teacher's and the student's, which describe their interests in the knowledge repository development. The interpretation of the cooperation between the teacher and the students is described based on game theory. A game situation, in which the teacher plays the role of the game leader and the students can play either in an organized sub-group or can play individually, is presented. Moreover, this cooperation is analyzed (time, workload) based on the proposed simulation approach. The possibility of assessing several variants of teacher's work in different educational situations by using the simulation model and the simulation software is described. The level of students' motivation can be determined. Finally we can conclude that there is a possibility to compare the expected costs that the teacher will bear considering the assumed repository development (working time) with the results achieved in the didactic process (number of students with a high level of competence - participating in the repository, number of students with an average level of competence etc.).

The presented paper is an extension of [9] and [19]. Both refer to the model of motivation. The current version of motivation model allows for more accuracy in student-teacher cooperation.

\section{The need for active cooperation of students and teachers in ODL}

In terms of significant reduction or absence of direct contact between the teacher and students, the work scope and the way they perform in the teaching and learning processes as well as in research and educational activities varies considerably. Changes occur due to various reasons [9]:

1. In a traditional learning situation didactic (teaching) material is a support for accumulating knowledge which is seen as necessary for a professional career, and which will remain relevant for a long time. This cannot be said for newer education dealing with new technologies such as computer science, management and business, productions areas, banking and new media technologies etc. [14].

2. In traditional teaching approach learning might look like "the process of intelligent production", except when a student finds out that the learned knowledge lacks being reflected in the context, and he/she has no skills to use it.
The teacher might be aware of the problem and can take it into account during direct contact with the students.

3. The main conventional tool for establishing motivation used by the university systems is knowledge assessment process (tests, exams, grades etc.).

4. The design and relevance of didactic materials have a secondary role in a traditional teacher's professional role (research is priority one), but it is still the main engine in a student's cognitive learning processes.

Cognitive processes are characterized by high entropy. However, during direct contact with a student the traditional teacher using his/her professional competence can reduce entropy as a result of certain didactic or pedagogical methods, or in other words, be able to manage a student's cognitive processes within certain limits. In this case efficiency of teaching/ learning management depends on the intensity of the contacts, abilities of students, as well as of the teacher's pedagogical and communicative skills [12].

Różewski and Zaikin [9] find that the importance of the role of didactic materials in ODL is greatly increased, as in ODL teachers have to substitute direct contact and exchange of information between teacher and student. This imposes new requirements on didactic materials as sources of information not only on learning topics, but also on teaching and learning strategies as well as the whole learning process as a combination of communication, interaction and knowledge production [15].

The big challenge for ODL teachers is to design and prepare the teaching materials for ODL. The needed resources can be listed: professional knowledge related to the subject, pedagogical skills, knowledge and experience about teaching within the frame of ODL, time for developing and designing new material which will fit the ODL demands. A solution could be to actively involve the students in establishing knowledge as a common process of teaching/learning activities.

Ontology is widely used for knowledge representation and there are ontology description languages, and programs to operate them [11]. More detailed design of didactic materials based on ontology models of subject knowledge is described in [13]. Design, preparing and access to the didactic materials in an ODL computer environment (creating e.g. a repository) require specialized knowledge and time from the involved teachers. Therefore, the following problems appear when developing ODL: how can teachers be motivated to carry out additional work to establish and maintain didactic materials in repository up to date. A repository is defined here as a virtual or digital library of didactic materials, assigned for learning of a subject or domain area [16].

One way to minimize the problem is to encourage students to supplement the repository with new materials on the proposed teacher topic within a pre-defined ontological domain model. In the ODL situation the students independently could develop the ontology of the proposed theme and then make it compatible with the conceptual structure developed by a teacher. Performing this task requires extensive use of highly demanding operations such as generalization, classification, induction, deduction, and promotes deep mastery of the conceptual apparatus of the subject area. Coombs et al. [17] discuss the advantages 
of using an ontological approach to learning and teaching. The main advantage of this method is recognized as the development of analytical skills of the students and a systematic vision of wide fields of knowledge objects and their applications. When performing this task, the students involved should be granted priority when requesting the teacher's consulting. For students who work together with highly skilled teachers, this activity promotes self-esteem and motivates self-education activity.

Another way to involve students in active learning is to create a game situation [18], which requires a connection between different kinds of knowledge. A distinctive feature of the ontology developed for educational purposes is that the ontology graph contains fragments corresponding to different types of subject knowledge: theoretical (what is this?) and the procedural (how to do this?). Theoretical vertices describe the semantics of concepts and their relationships, and the procedural ones - test tasks associated with the corresponding path in the graph. The project task, to develop the domain ontology with both types of vertices, can be represented as a game with total win and distribution points depending on student participation and performing. Overall gain considered is the number of vertices of both types, added to the domain ontology graph, which are stored in the repository. The teacher plays the role of the head of the game, students are combined into sub-groups or they can play individually. Teacher's motivation is the possibility of an extension and updating of the repository by independent work of students. Students' motivation is the joint study of the subject under supervision of a teacher - live chat, cognition through competition, stress reduction compared to traditional testing, choice possibility, etc. The game can be carried out remotely [19]. Final assessment depends on the task complexity, participation in the project, the number of ECTS points etc. The students will progress from a simple task to more complicated task due to the mechanism of motivation triggered by a teacher.

\section{Interpretation of the motivation model in learning processes}

In traditional teaching, based on traditional didactic materials, the average activity of students' involvement in the learning process is weak, and the accumulation of material in a repository for subsequent use is small. However, the teacher's time costs are lower. In ODL the student can be involved in learning process in two ways:

1. Independent development and update of the repository by students. Then the repository is using as a base didactic material for developing knowledge in ODL. The costs of the teachers time will increase significantly, but it is justified by the possibility of obtaining results for further improvement and modernization of the learning processes.

2. Student is taught how to use the ontological approach for representation and development of knowledge in any domain area, and how to organize games as a way of self-learning in a given subject area. This approach might result in a significant increase of students' activity. The time costs of the teacher are comparable to the first case. But in the second case the students not only acquire knowledge, but also competence, and the teachers in return obtain new improved didactic material to be used in the ontological approach and in game tools.

For evaluation and assessment the teacher can use the linguistic scales to evaluate the proposed alternatives. In each situation the teacher can give preference to any of these alternatives, as each of them is connected with its various temporal and intellectual costs as well as other preferences. The teacher's intellectual cost is related to checking and evaluation of the complex tasks. The more students choose the complex tasks, the more intellectual cost the teachers have to spend for their checking and evaluation.

One of the impact factors of the teachers' choice is the evaluation to get the final result at the end of the learning cycle in the form of a specific indicators such as:

- average index of student performance;

- index of students' activity and independence of choosing types of task, e.g. the traditional way of learning and testing, the work together with the teacher on the use of the ontological approach for repository development, an engaging in joint or individual learning projects.

- the index of repository filling by didactic materials is created on the principle of "actual domain ontology" plus the base of learning projects presented as "best practices".

Availability of such data allows for further research, not only in teaching methods, but also in the field of artificial intelligence and the development trends of corresponding knowledge domains. This in turn is a problem raised for discussion in numerous papers [20].

The modern system of assessment of the teacher's professional activities requires wide participation in international scientific research. In the proposed game this can play an important role for evidence based evaluation of the learning process.

Scoring system used for evaluation of students' work is the teacher's prerogative and it can be addressed to the student groups in the beginning of the learning process, but a student's choice will also depend on their personal preferences:

- leadership skills,

- the possibility of increasing the total average Diploma score,

- possibility of participation in individual grants due to personal contribution to "best practices".

The proposed approaches to learning allow for realizing motives and preferences of both students and teachers, so we can form two motivation models and examine their mutual influence.

Choice making is a cognitive process and it cannot be directly observed. This means that the relationship between a person's preferences in motives when choosing the result of his/ her actions is very difficult to define. Nevertheless, the choice of motive can be evaluated by registering the outcomes.

A motivation model in the described learning situation can be represented as a game scenario, in which the activities of the teacher and students will respond to their preferences in 
choosing the above alternatives. The proposed model is based on the following assumptions:

- the elements of the described chain and its alternatives are predefined,

- choice of a job in the game is made once,

- for each task selected by a student, the degree of its complexity and the corresponding number of ECTS is known,

- the content of selected task can be displayed on an ontology graph of the studied subject as a set of vertices with the theoretical and procedural knowledge, which constitute a certain portion of competence,

- students and teachers will have the possibility to know the results of the partners' choices in the game.

\section{Statement of the motivation problem in a particular learning situation in ODL}

In the proposed game scenario each participant has the possibility of free choice among the available alternatives. The main result of the game is to develop an ontology graph of studied subject by means of adding new vertices connected with the existing ones. These new vertices submit new theoretical knowledge and/or skills acquired in task performing. The goal of the teacher is to attract as many students to this kind of tasks under the following constraints: the total number of hours assigned for subject in scheduling and time interval allotted for the game.

Each student defines the result of the game in the range of the following features: from lowest allowable assessment on the subject (in the traditional way of studying) to the highest result for active and successful participation in the project and "best practices". A teacher distributes the supervision time among students at his/her discretion, but at the condition of minimum mandatory quota for each student. In this situation it may be assumed that a teacher is interested to spend the most of his/her time and intellectual resources on joint work with best students. They will contribute to the updating and expansion of the repository, which provides the basis for compiling the results in studied subject, with an option to use grants or publications. This aspect motivates the teacher to advance students to more complex work and to spend more resources on their performance. In this case there is a possibility to use the results in teacher's and students' common research. Thus, the proposed scenario allows the teacher and each student to formulate the conditions to choose their strategies in the learning process based on individual preferences.

The teacher's objective will be to maximize possible extension of the repository through the involvement of a larger number of students for competitive performance of complex project tasks under the restrictions on total time of supervision. Considering students' preferences it may be defined within two extreme cases:

a) the students prefer to perform the simplest tasks, minimizing their time and intellectual costs and getting the lowest possible scores. In fact, these students do not participate in the repository extension.

b) the students prefer to participate in the repository extension of knowledge acquired in the project task under restrictions to their own time and intellectual resources. Every student intends to use the maximum of teacher's time of supervision competing for it with other students in this group.

In case a) the teacher and students with minimal effort will complete the learning process, but indicators, such as average achievement and filling of repository will be low, although satisfying the low boundary conditions (formal compliance schedule and personal quota for supervision). In case b) the teacher and students will spend far more effort, but a great part of successfully completed tasks will be included into the repository and the average achievement will be higher. At the same time in case b) learning will be aimed not only at understanding the theoretical material, but also the ability to operate them (i.e. mastering of didactic material at the level of competence).

Thus, the aim of the game is the maximum extension of repository with original results of teacher's and students' joint work under restrictions on their time resources and compliance with preferences of all participants of the game. Motivation problem is considered in particular educational situations, when we are dealing with special didactic material for particular participants of the learning process. For this we will use the term "learning situation", which is represented in Fig.1.

The formal model which describes the competence-oriented education process [15] has the following structure.

\section{Basic components of the educational situation}

a) participants of the learning process $\{\mathrm{N}, \mathrm{S}\}$, where

$\mathrm{N}$ - teacher,

$S=\left\{s_{j}\right\}-$ set of students/project team, where

$\mathrm{j}=1,2, \mathrm{j}^{*}$ - index of student.

The process of students' arrival to ODL system can be described by

$\mathrm{x}$ - distribution law,

$$
\pi(S)=\{\chi, \lambda\}, \text { where }
$$

$\lambda$ - intensity of arrival,

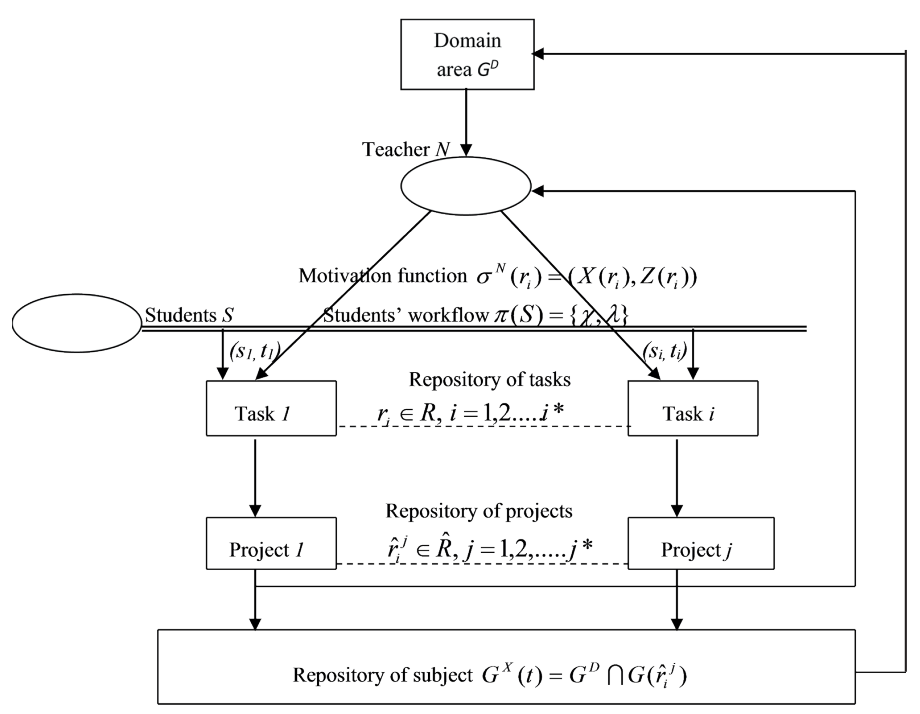

Fig. 1. Process of choice and execution of project tasks by students (educational situations) 
b) ontology graph of the domain area $G^{D}$

$$
G^{D}=\left\{W^{D}, L^{D}\right\}, \text { where }
$$

$W_{D}$ - nodes/concepts/learning objects of the graph,

$L_{D}$ - graph edges (relations between concepts),

c) ontology graph of the course $G^{C}$

$$
G^{C}=\left\{W^{C}, L^{C}\right\} \text {, where } W^{C} \subseteq W^{D}, L^{C} \supseteq L^{D}
$$

d) set/repository of the tasks R

$R=\left\{r_{i}^{k}\right\}$, where

$r_{i}^{k}$ - task ' $\mathrm{i}$ ' consisting for competence portion ' $\mathrm{k}$ ',

$\mathrm{i}=1, \ldots, \mathrm{i}^{*}-$ index of task,

$\mathrm{k}=1, \ldots, \mathrm{k}^{*}$ - index of acquired competence/competence portion

e) parameters of tasks $\Pi\left(r_{i}^{k}\right)$

$$
\Pi\left(r_{i}^{k}\right)=\left\{Q\left(r_{i}^{k}\right), A\left(r_{i}^{k}\right)\right\}, \text { where }
$$

$Q\left(r_{i}^{k}\right)$ - the level of complexity of a task, which can be expressed in a binary scale

$$
Q\left(r_{i}^{k}\right)=\left\{\begin{array}{l}
1, \text { if task } \mathrm{r}_{\mathrm{i}}^{\mathrm{k}} \text { is a complex one } \\
0, \text { otherwise }
\end{array}\right\}
$$

or in numerical scale (e.g. number of concepts from set $W^{D}$ included in the task),

$A\left(r_{i}^{k}\right)$ - topicality of the task - characteristic of a task assigned by the teacher, which can be expressed with a binary scale,

$\mathrm{A}\left(\mathrm{r}_{\mathrm{i}}^{\mathrm{k}}\right)=\left\{\begin{array}{l}1, \text { if task } \mathrm{r}_{\mathrm{i}}^{\mathrm{k}} \text { is chosen by the teaher to develop the repository } \\ 0, \text { otherwise }\end{array}\right\}$

The teacher places an up-to-date, properly solved task in the task repository R;

f) repository of the projects assigned by teacher for saving of subject knowledge $\mathrm{X}$

$$
X=\left\{\hat{r}_{i}^{k}\right\}, \text { where }
$$

$\hat{r}_{i}^{k}$ - executed task $r_{i}^{k}$, included in repository

g) state of the repository $\mathrm{X}$ in time t, $G_{X}(t)$

$$
G_{X}(t)=\left\{W_{X}(t), L_{X}(t)\right\} \text {, where }
$$

$W_{X}(t) \subseteq W^{C}-$ set of vertices of graph $G_{X}(t)$,

$L_{X}(t) \subseteq L_{C}-$ set of arcs/edges of graph $G_{X}(t)$,

$t \in\left[t_{0}, T_{c}\right]$ - time interval assigned for acquiring of the competence.

\section{Decision parameters}

a) student's decision parameter: binary function of the task choice $y\left(r_{i}^{k}, s_{j}\right)$

$$
y\left(r_{i}^{k}, s_{j}\right)=\left\{\begin{array}{l}
1, \text { if student } s_{j} \text { chooses tast } r_{i}^{k} \\
0, \text { otherwise }
\end{array}\right.
$$

b) teacher's decision parameter: binary function of assignment of the task/project to repository $\delta^{N}\left(\hat{r}_{i}^{k}\right)$

$\delta^{N}\left(\hat{r}_{i}^{k}\right)=\left\{\begin{array}{l}1, \text { if project/task } p_{\mathrm{i}}^{\mathrm{k}} \text { is selected for repository } \\ 0, \text { otherwise }\end{array}\right.$

\section{Criterion and objective functions}

Let us define the following variables:

a) ontology graph of the task/project

$$
G\left(\hat{r}_{i}^{k}\right)=\left\{W\left(\hat{r}_{i}^{k}\right), L\left(\hat{r}_{i}^{k}\right)\right\},
$$

where

$W\left(\hat{r}_{i}^{k}\right)$ - set of the vertices of the graph, $W\left(\hat{r}_{i}^{k}\right) \subseteq W^{C}$

$L\left(\hat{r}_{i}^{k}\right)$ - set of the arcs of the graph, $L\left(\hat{r}_{i}^{k}\right) \subseteq L^{C}$ b) knowledge gain under replacement of task/project $\hat{r}_{i}^{k}$ in repository $X, \Delta G_{X}\left(\hat{r}_{i}^{k}\right)$

$$
\begin{aligned}
& \Delta G_{X}\left(\hat{r}_{i}^{k}\right)=\left\{G_{X}(t) \cap G\left(\hat{r}_{i}^{k}\right)=W_{X}(t) \cap W\left(\hat{r}_{i}^{k}\right),\right. \\
& \left.L_{X}(t) \cap L\left(\hat{r}_{i}^{k}\right)\right\}
\end{aligned}
$$

c) numerical characteristic of knowledge gain in repository $\left|\Delta G_{X}\left(\hat{r}_{i}^{k}\right)\right|$

$$
\left|\Delta G_{X}\left(\hat{r}_{i}^{k}\right)\right|=\delta^{N}\left(\hat{r}_{i}^{k}\right) \mid W^{C} \bigcap W\left(\hat{r}_{i}^{k)} \mid,\right.
$$

$\left|W^{C} \cap W\left(\hat{r}_{i}^{k}\right)\right|$ - number of common vertices in the ontology graphs $G^{C}$ i $G\left(\hat{r}_{i}^{k}\right)$

d) teacher resources expenditures $Z^{N}\left(\hat{r}_{i}^{k}\right)$, e.g. consultation time for task/project $\hat{r}_{i}^{k}$ executing

$$
Z^{N}\left(\hat{r}_{i}^{k}\right)=\alpha_{N} \mid G\left(\hat{r}_{i}^{k)} \mid\right.
$$

where

$\alpha_{N}$ - weight coefficient of teacher expenditures.

\section{Objective function of the teacher}

a) total gain of repository $X$ on the interval of acquiring of the competence $\Delta G_{X}^{\Sigma}\left(0, T_{0}\right)$

$$
\begin{aligned}
& \Delta G_{X}^{\Sigma}\left(0, T_{0}\right)= \\
& =\sum_{i=1}^{i^{*}} \sum_{k=1}^{k^{*}} \sum_{j=1}^{j^{*}} \delta^{N}\left(\hat{r}_{i}^{k}\right) y\left(r_{i}^{k}, s_{j}\right) G_{X}(t) \cap G\left(\hat{r}_{i}^{k}\right)
\end{aligned}
$$

b) numeric characteristic of total knowledge gain in repository $\left|\Delta G_{X}^{\Sigma}\left(0, T_{0}\right)\right|$

$$
\begin{aligned}
& \left|\Delta G_{X}^{\Sigma}\left(\hat{r}_{i}^{k}\right)\right|= \\
& =\sum_{i=1}^{i^{*}} \sum_{k=1}^{k^{*}} \sum_{j=1}^{j^{*}} \delta^{N}\left(\hat{r}_{i}^{k}\right) y\left(r_{i}^{k}, s_{j}\right)\left|W^{C} \cap W\left(\hat{r}_{i}^{k}\right)\right|,
\end{aligned}
$$

$\left|W^{C} \cap W\left(p_{i}^{k}\right)\right|$ - the number of common vertices in ontology graphs $G^{C}$ i $G\left(p_{i}^{k}\right)$

c) total expenditures of the teacher on interval of acquiring of the competence $Z_{X}^{\Sigma}$

$$
Z_{N}^{\Sigma}=\sum_{i=1}^{i^{*}} \sum_{k=1}^{k^{*}} \sum_{j=1}^{j^{*}} \alpha_{N} y\left(r_{i}^{k}, s_{j}\right)\left|W\left(\hat{r}_{i}^{k}\right)\right|,
$$

where

$\alpha_{N}$ - weight coefficient of the teacher's expenditures,

$\left|W\left(p_{i}^{k}\right)\right|$ - the number of vertices in ontology graph of task/ project $G\left(\hat{r}_{i}^{k}\right)$

d) objective function of the teacher $\Phi^{N}$ : total gain of repository $X$ on the interval $\left[t_{0}, T_{c}\right]$ of acquiring of the competence, taking into account expenditures of the teacher

$$
\begin{aligned}
\Phi^{N} & =\left|\Delta G_{X}^{\Sigma}\left(0, T_{0}\right)\right|-Z_{N}^{\Sigma}= \\
& =\sum_{i=1}^{i^{*}} \sum_{k=1}^{k^{*}} \sum_{j=1}^{j^{*}} y\left(r_{i}^{k}, s_{j}\right)\left\{\delta^{N}\left(\hat{r}_{i}^{k}\right)\left|W^{C} \cap W\left(\hat{r}_{i}^{k}\right)\right|\right. \\
& \left.-\alpha_{N}\left|W\left(\hat{r}_{i}^{k}\right)\right|\right\}
\end{aligned}
$$




\section{Objective function of the student}

objective function of student $\Phi\left(s_{j}\right)$ : number of ECTS points, taking into account expenditures of the student for execution of task/project $\hat{r}_{i}^{k}$

$$
\begin{aligned}
\Phi\left(s_{j}\right) & =\sum_{i=1}^{i^{*}} \sum_{k=1}^{k^{*}} y\left(r_{i}^{k}, s_{j}\right) \gamma^{N}\left(\hat{r}_{i}^{k}\right)\left|W^{C} \cap W\left(\hat{r}_{i}^{k}\right)\right|- \\
& -\left|\beta^{S} W\left(\hat{r}_{i}^{k}\right)\right|,
\end{aligned}
$$

where

$\gamma^{N}\left(\hat{r}_{i}^{k}\right)$ - number of ECTS points assigned by the teacher for the task/ project $\hat{r}_{i}^{k}$,

$\left|W^{C} \cap W\left(\hat{r}_{i}^{k}\right)\right|$ - numerical characteristic of gain of repository for task/project $\hat{r}_{i}^{k}$,

$\left|W\left(\hat{r}_{i}^{k}\right)\right|$ - numerical characteristic of complexity of task/ project $\hat{r}_{i}^{k}$,

$\beta^{S}$ - weight coefficient of student's expenditures

\section{Constraints}

a) summary resources (time-related, technical, didactic, staff) offered to students for solving tasks:

$$
\bar{Z}_{o}=\sum_{s_{j} \in S} \bar{z}\left(r_{i}^{k}\left(s_{j}\right)\right) y\left(r_{i}^{k}\left(s_{J}\right)\right) \leq Z_{\Sigma}^{N},
$$

where

$\bar{z}\left(r_{i}^{k}\left(s_{j}\right)\right)$ - resources appointed to student $s_{j}$ for solving task $r_{i}^{k}$,

$y\left(r_{i}^{k}\left(S_{J}\right)\right)=\{1,0\}-$ binary function of choice the task $r_{i}^{k}$ by student $s_{j}$,

$\bar{Z}$ - summary resources for the subject lead by the teacher.

b) calendar interval $\tau \in\left[0, T_{0}\right]$, appointed to students for choosing and solving tasks

$$
\min _{j} \underline{\tau}\left(r_{i}^{k}\left(s_{j}\right)\right) \geq 0, \max _{j} \bar{\tau}\left(r_{i}^{k}\left(s_{j}\right)\right) \leq T_{0},
$$

\section{where}

$\underline{\tau}\left(r_{i}^{k}\left(s_{j}\right)\right), \bar{\tau}\left(r_{i}^{k}\left(s_{j}\right)\right)$ - appropriate moments to start and end solving task $r_{i}^{k}$ by student $s_{j}$.

Two extreme cases of the teacher and student motivation functions are shown in Fig. 2.

Motivation of students in both cases, is described as a linear function. Depending on whether it is the motivation ambitious or non-ambitious students, this function is respectively increasing or decreasing.

Identifying the teacher motivation assumes the function of this motivation will be built for each group of students. Its shape will depend on which group of students the teacher will work at a given time. The curve describing the motivation function of the teacher in the general case takes the form of non-linear and convex. In the case of non-ambitious students, the teacher motivation function is increasing due to the need for continuous motivating students solving more difficult tasks and requiring more time. Otherwise, the students will be ambitious and strongly determined to achieve a high score, which will result in a decreasing function. Due to existing restrictions the teacher must inhibit the motivation of students. Distribution of this function is related to the time constraints which are connected the teaching process.
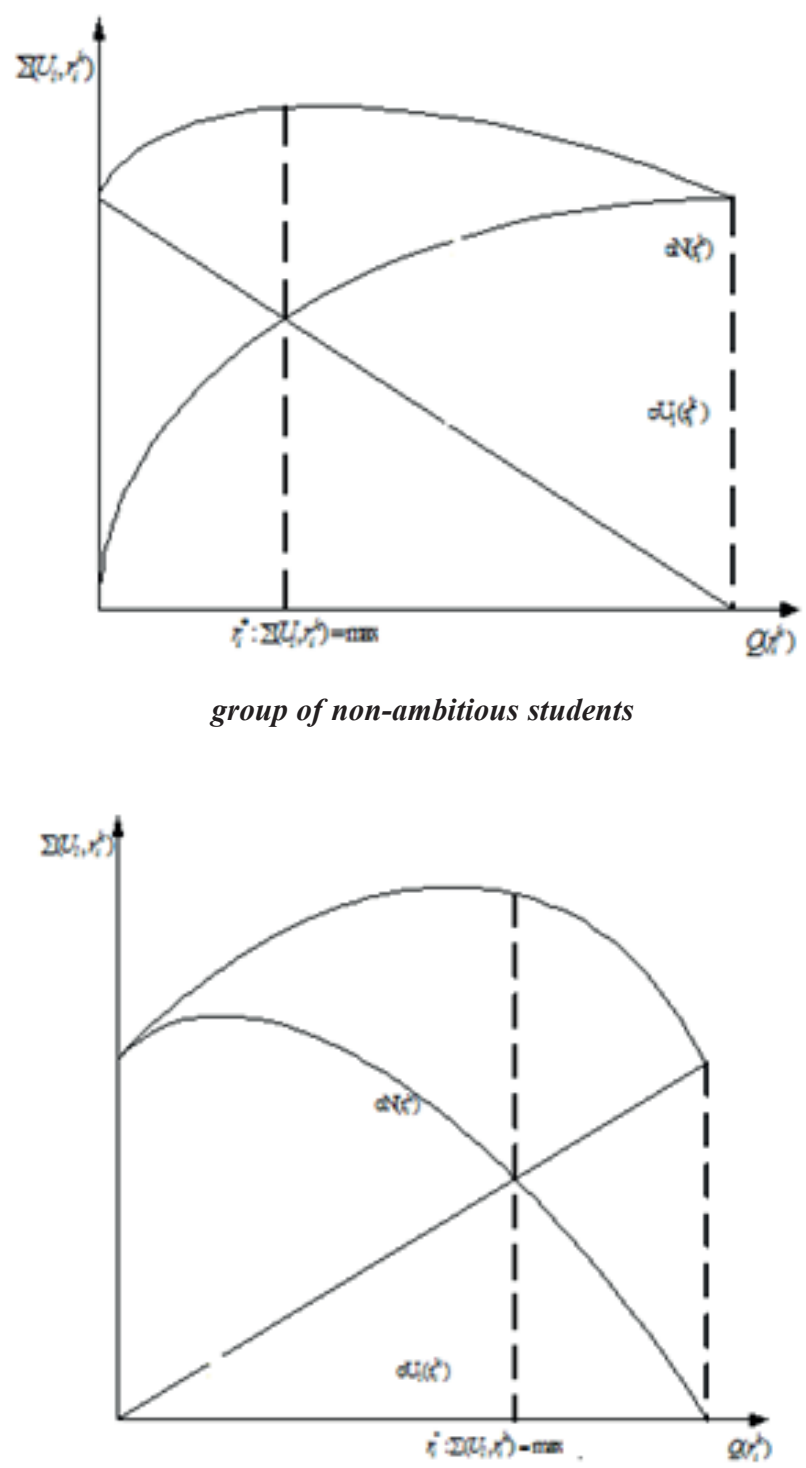

group of-ambitious students

Fig. 2. The shape of the motivation function during the teaching process

The nature of the motivation function indicates that it is non-linear. The shape of this function results to the rules for summarizing the functions of teacher and student motivation. Both components of the objective functions depends on the same argument as opposed. The summarizing function of student motivation reaches its maximum value when making the optimal choice task - optimal level of the task complexity.

\section{Motivation model interpretation in terms of games theory}

Some initial remarks about the motivation model interpretation in terms of games theory can be found in [19]. Following that publications we can assume that proposed model refers 
to the class of games with a defined number of steps and full information about participants' activities. Moreover, based on game theory terminology the motivation model can be seen as incentive task, where motivation management signifies direct rewarding an agent (student) for his actions.

The game model which is described in [19] and can be solve by algorithms described in [20] and [24] has the following structure:

$M$ - a set of acceptable motivation methods,

$Y(\sigma)$ - a set of game solutions (strategy of agents having balance in their motivation method $\sigma$ ).

Management (motivation) effectiveness means obtaining maximum value of the objective function $U(\sigma)$ on an appropriate set of game solutions.

$$
U(\sigma)=\max _{y \in Y(\sigma)} f(\sigma, y),
$$

where $\sigma$ is a motivation function of the centre, $y$ is a binary argument of agent's choice.

The task of optimization is about searching for an acceptable motivation function with maximum effectiveness:

$$
\sigma^{*} \in \operatorname{Arg} \max _{\sigma \in M} U(\sigma)
$$

At the moment of the decision making (motivation function for the centre and student's decision function for the agent) the objective functions and acceptable actions of all participants are known. Let us define the game scenario:

Step 1. The centre has the right of the first move, when it chooses a motivation function, before the agents choose activities that optimize their objective functions. The centre (teacher's) objective function $\Phi^{N}$ is the difference between expected income $X$ (gain of repository) and the summary reward paid to the agents (sharing one's own resources $Z_{N}^{\Sigma}$ )

$$
\Phi^{N}=\mathrm{X}-Z_{N}^{\Sigma}
$$

The centre's choice of a motivation function takes place in condition of uncertainty and foreseeing random characteristics of the basic students' knowledge and parameters of the process of their arrival. Therefore centre can use the principle of minimal guaranteed result and compensatory function of restitution , that means lack of centre's income. In that case centre's objective function has negative value and represents the minimal costs of centre when working with agents

$$
X=0, \Phi^{N}=-Z^{N}=\min
$$

Therefore the center creates motivation function in condition of minimal guaranteed result, $-Z^{N}=$ min, which cannot exceed admissible centre's costs $-Z_{N}^{\Sigma}$.

Step 2. Agents choose their strategies independently and do not exchange information or wins, this signifies that we are dealing with a relational dominant strategy (RDS). By objective function of each agent $\Phi^{S}$ we understand the difference between his/her reward obtained from the centre $\gamma^{N}$ and the losses connected to solving the task $w^{s}$

$$
\Phi^{S}=\gamma^{N}-w^{S}
$$

If income of centre $X=0$, and reward of each agent only compensates his/her estimated costs $\gamma^{N}=w^{S}$, then the objective function of each agent $\Phi^{S}=0$.

Step 3. On the base of result of the agents' selection the centre can adjust the function of motivation to achieve its maximum value of the objective function. In addition the centre can verify restrictions on the total resources provided by agents

$$
\begin{gathered}
\Phi^{N}=\mathrm{X}-Z_{N}^{\Sigma}=\max \\
Z_{N}^{\Sigma} \leq \hat{Z}_{N} .
\end{gathered}
$$

Step 4. Agent makes the final selection of a task on the base of his/her preferences while maximizing its objective function

$$
\Phi^{S}=\gamma^{N}-w^{S}=\max
$$

\section{Simulation model of teacher and student collaboration}

The assumed approach to modelling the process of acquiring competences can be depicted as a set of three components: the model of defining competences, the motivation model and the simulation model [25]. Interrelationship between these models is presented in Fig. 3.

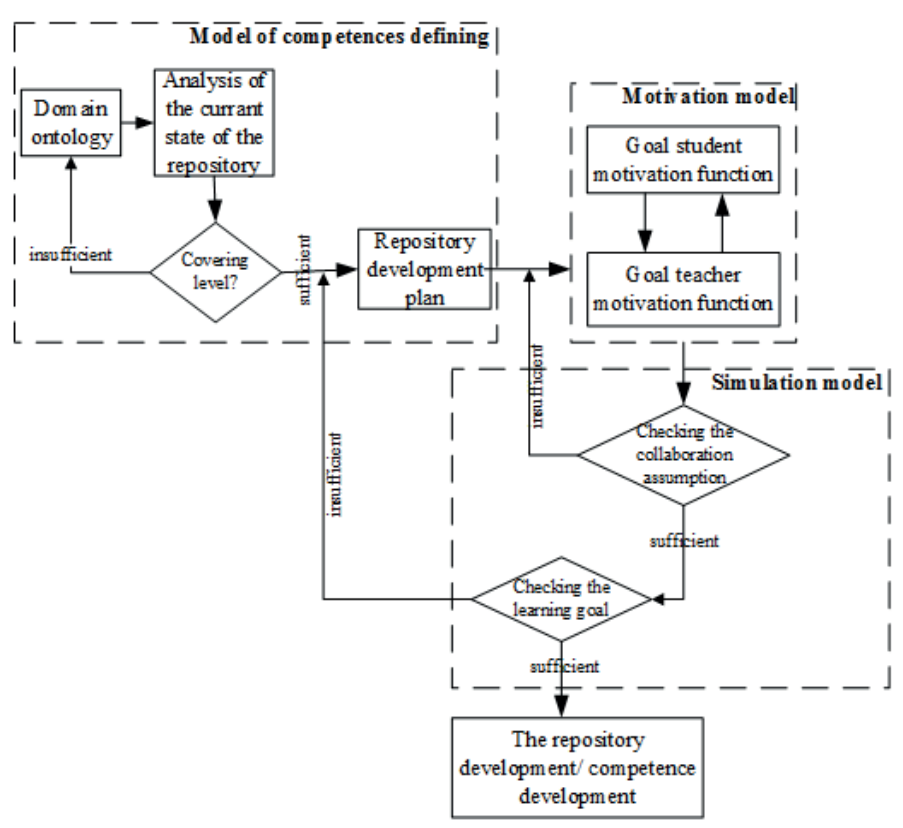

Fig. 3. Process of choice and execution of project tasks by students (educational situations) [28] 
Integration of the three components mentioned above allows for defining the scope and goal of learning, the conditions of cooperation between the participants of the learning process, and the possibilities of analysing the process and influencing the teacher's existing strategy of working with the students. Thus the proposed approach to modelling the process of acquiring competences appears to be a solution in which:

- the structure of competence and the method of assessing the development of competence (with the use of an ontology graph and a repository) is defined,

- conditions of competence development are defined (with the use of the motivation model),

- there is a possibility to compare the expected costs that the teacher will bear considering the assumed repository development (working time) with the results achieved in the didactic process

The proposed formalisation of cooperation between participants of the learning process during repository complementation indicates that quantitative analysis of this problem from the point of view of expected results and incurred costs is a difficult task. This difficulty is mainly caused by the fact that this process is related to behaviours and preferences of humans, which can change and are difficult to predict. For this reason simulation seems an adequate mechanism, which allows for obtaining information about the analysed object of study and is the basis for further activities related to the functioning of this object.

On the basis of the developed simulation model it is possible to study the adapted strategy of cooperation between the teacher and a group of students. The aim of the simulation is to assess if the expected repository development plan is possible to realise with the teacher working in a distance mode, with a specified distribution of student arrival, and a specified distribution of grading.

6.1. The procedure for the acquisition of personal competence. Within psychology there is a distinction between the mastery of operation and mastery of theoretical knowledge and acquisition of competences. Based on Woolfolk [26], we will try to present the process of acquiring competences based on a certain level of domain knowledge.

The aims of the execution procedure is an acquisition of competence training for students and collection of statistics, allowing for clarification of the individual process management model of teaching in the open distance learning system. The training needed to get the student through the mechanisms of the repository's virtual lab with the set of triplets: part of the description fields - a typical task - a typical solution, and the corresponding test task which is used to describe knowledge as an extended ontological model.

The task of testing should be interpreted in the terms contained in the proposed triplet. For proper identification of test task a disclosure of knowledge necessary to prepare a solution will be needed. The student's solution can be compared with the solution typically stored in triplet. Measurement of teaching consists not only of collecting statistics of personal data, but also analysing the interpretation of test tasks. The implementa- tion of a training session can be calculated using the following indicators: the percentage of correctly interpreted jobs, the percentage of correctly identified tasks, the percentage of correctly associated pairs of typical tasks and typical algorithms, the number of modules placed in the repository of knowledge, the number of sessions needed to perform a specific task, the number and complexity of the problems included in one job. The described indicators allow measuring teaching, based on skills of mastering theoretical knowledge and skills of its use in solving design tasks.

The procedure includes several steps, and the algorithm of its implementation depends on the software environment in which the repository will be created (Fig. 4).

Input data of the procedure:

1. Scope: subject / topic of teaching

2. The model of theoretical knowledge areas: a hierarchically ordered the basic concepts of the semantic network (graph).

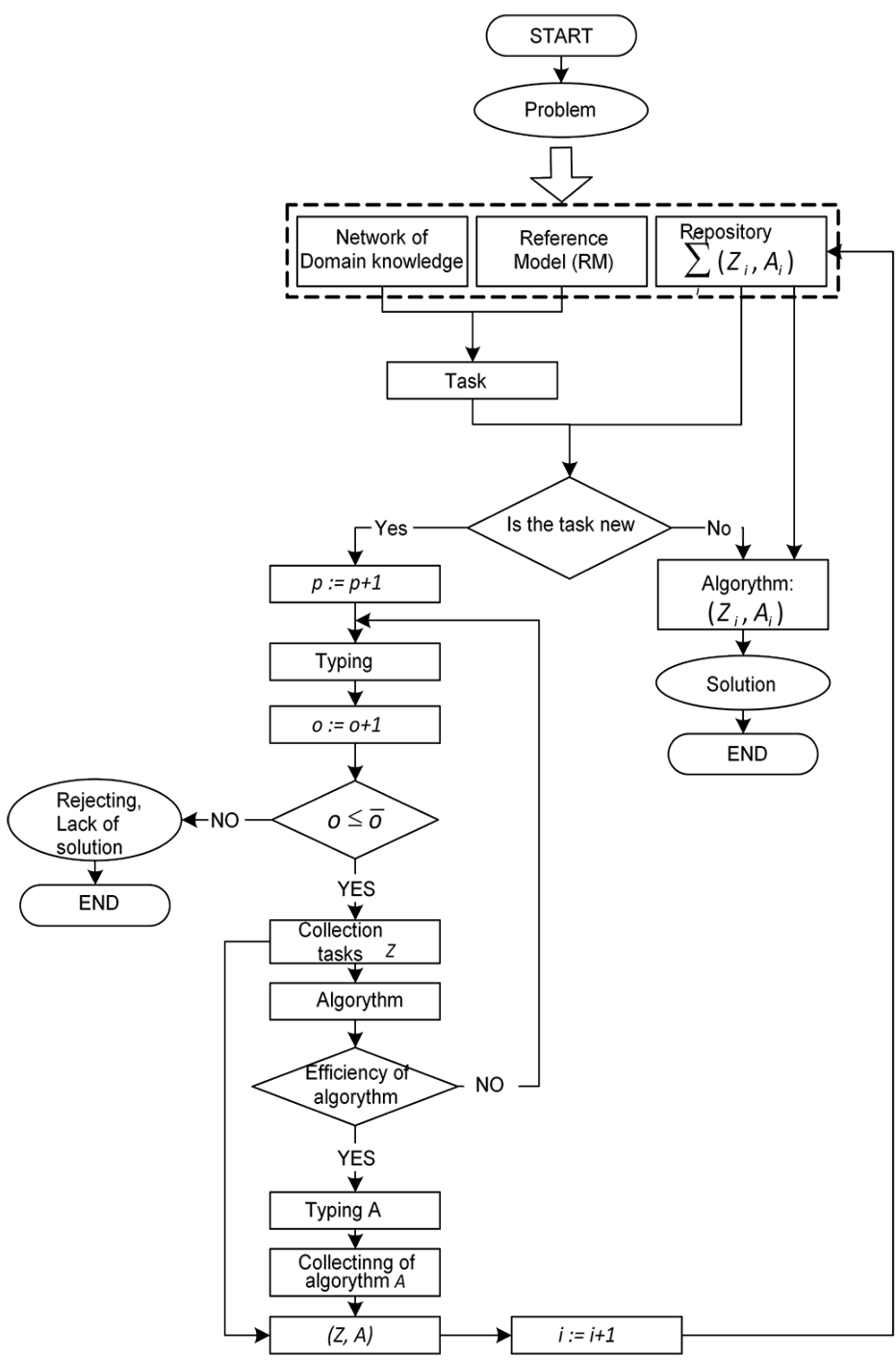

Fig. 4. The algorithm acquisition of competencies during a structured training 
3. The reference model to enable the use / assumption of the taxonomy studied during training problems; the presentation depends on the specific areas $\left(S_{p}\right)$.

4. Repository of solved tasks: typical task - a typical algorithm - the number of tasks. At the start of the session the repository can be empty or filled, depending on the topic and the student's personal learning goals.

The procedure for the acquisition of competencies during a structured training is done according to the following steps:

1) Analysis of the research problem. Determining whether the issue belongs to specific areas will allow to interpret the problem and to present it in terms of a particular model, and take into account existing knowledge of taxonomy $-\sum\left(Z_{i}, A_{i}\right), 1, \ldots i$ the formulation of the input problem. Depending on the educational situation the first step can be done in two ways:

a) independent formulation of the task by the student based on the ontological model $G_{p}$ and reference model of typical tasks;

b) analysis and identification of the tasks set by the supervisor of the project.

2) Analysis and systematizing of experience. A comparison between the input tasks with the tasks placed in the repository. The result is to determine the path that must be used to solve the problem either the way to develop an algorithm.

3) Typing of input tasks. Preparation of the task passport in the repository language (meta information in an XML).

4) The collection of the input task passport in the working memory of training session.

5) Developing of own algorithm for solving the task. The algorithm can be described using standard pseudocode or presented as a simulation task.

6) Execution of algorithm. The input data should be selected directly from the text of the analysed problem or pulled during its interpretation.

7) Evaluation of the effectiveness of the algorithm. At this stage the interpretation of results is made in the context of the output of algorithm (in terms of solved problem).

8) Typing of the developed algorithm. Preparation of the solution algorithm passport in the repository (meta information in an XML document).

9) The collection of algorithm passport in working memory of training session.

10) Preparing the knowledge module in the form of record in repository. At this stage teacher has to fill in a repository form, including: track keywords of the domain knowledge, matching the given problem, the task passport and passport algorithm.

11) Supplementing of existing repository. Required level of supplement depends on the subject, purpose and stage of teaching and must be given by the teacher to each student.

Described training is one of the traditional tools to collect statistics in the course of self-education students. However, the proposed structure for the fulfilment of the repository has several advantages:

- corresponds with the cognitive meaning of the competency structure,

- represents a system approach to a knowledge ontological model,

- enhance the ability to structure theoretical knowledge and connect it with results of student's own experience

A similar idea is used in simulators, the aim of which is to teach the use of complex equipment repair and machinery. The proposed method of domain area describing the structure and the content of repository, and allows students to master the complex theoretical knowledge while the teacher is absent. In this case, a chain "typical task-typical solution" is represented at the level of a mathematical reference model, which depends on the specific subject and purpose of education.

This procedure is a model skeleton in the course of training related to a specific topic. The ontological model, repository and the task should be completed with relevant teaching materials. An additional variant of the described approach to the structure and contents of the repository is associated with the formation of a virtual laboratory. It is designed to conduct simulation experiments, when the assumption of the task simulation, execution and interpretation of the results of the experiment needs the cooperation of experts located at a distance.

6.2. Ontological graph of the subject/course consistent with the structure of competence. The first ontologies were built for the needs of engineering knowledge and they began to emerge in the 80 s of XX century. Intensive works on ontology resulted in the development of its various categories. Proposed by Guarino [27] division includes: general ontology (a top-level ontology), domain ontology, task ontology, and application ontology. Each of them has a different level of generalization. Domain ontology describes domain-area knowledge characteristic, e. g. medicine, pharmacy, law, music. The terms used in domain ontology are the result of specialization of concepts defined in general ontology. Task ontology describes the dictionary of a particular task or activity, e. g. diagnosing, scheduling, specializing terms stemming from the general ontology. In contrast to the domain ontology, in this case for solving the problem concepts from various fields can be used. Application ontology includes the concepts that are required for the description of knowledge for individual applications. It specializes the concepts of domain and tsk ontologies for the given application.

For example of ontological graph the subject/course "Discrete mathematics", provided for specialty "Computer Science" is represented in Fig. 5.

Practical part of the course/ subject includes a number of tasks. There are two kinds of the tasks: simple and complex ones. They differ in labour complexity of implementation and reward-number of ECTS, which student will get for correct execution of the task. In general the teacher can define any number of classes of tasks, which differ in degree of complexity.

6.3. The supporting tools for determining the level of student's motivation is the linguistic data base. Recognition of 


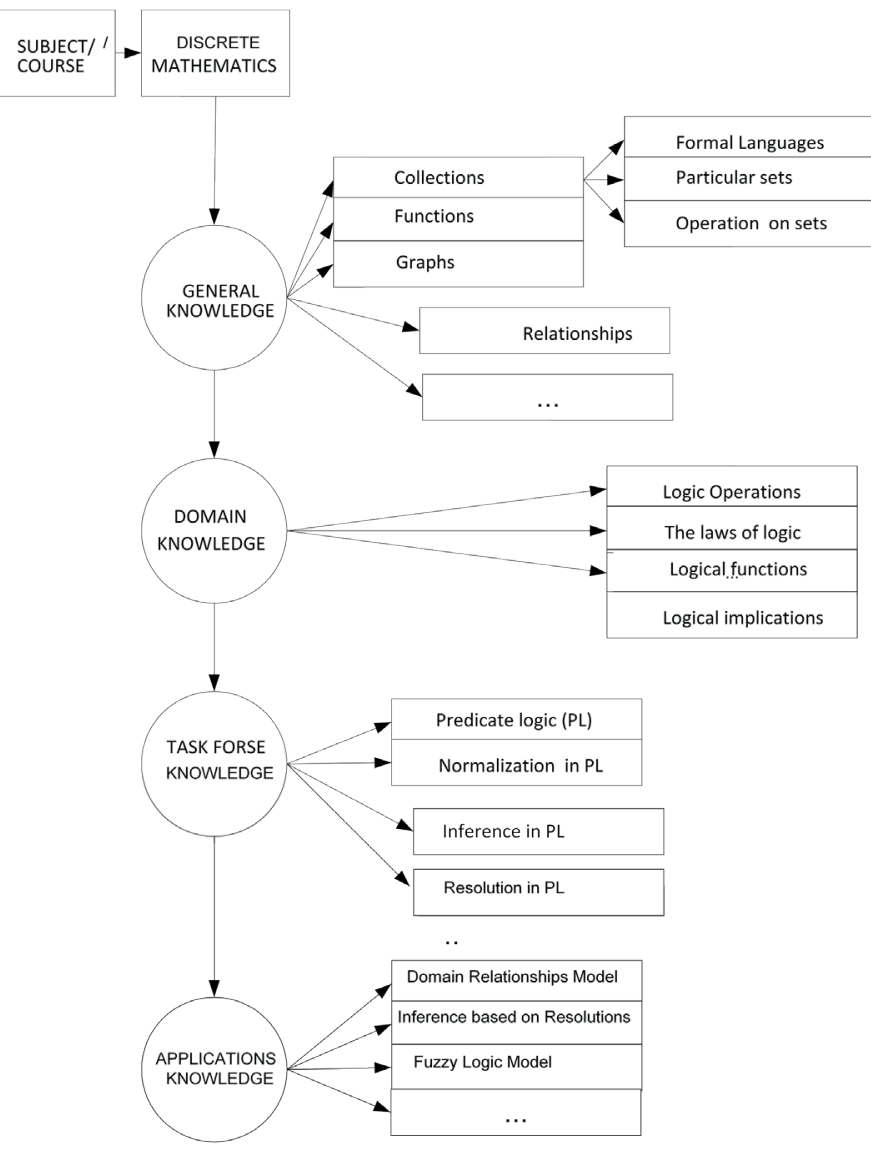

Fig. 5. Ontological graph of a subject/course "Discrete Mathematics"

teacher and student motivation is the basis to determine whether the existing restrictions on the competence acquisition process they can achieve required competence level and at what cost. Checking these constraints is done using simulation.

Basis to estimate input value of simulation model is expected activity of participants resulting from their motivation. Therefore, recognition of this motivation is necessary to perform the simulation/experiments [28].

Teacher motivation identification is the task so easy that he is one and could recognize his motives. More complicated issue is to assess students' motivation, because there are many students and each of them has a different level of motivation. Therefore, it is proposed to use the mechanism to determine the motivation in the form of linguistic knowledge base. In the presented example it includes a set of student's motivation parameters, which can be based on the experience of the teacher. A linguistic data base aimed at supporting the process of identifying students' motivation is presented in Fig. 6.

The structure of the linguistic data base created in order to support the process of identifying students' motivation is presented in Fig. 7.

The supporting tools which determine the level of student's motivation is the linguistic knowledge base [29]. For selected factors influencing the motivation we developed distribution functions of linguistic quantifiers. Two distribution functions of the features are presented in Fig. 8.

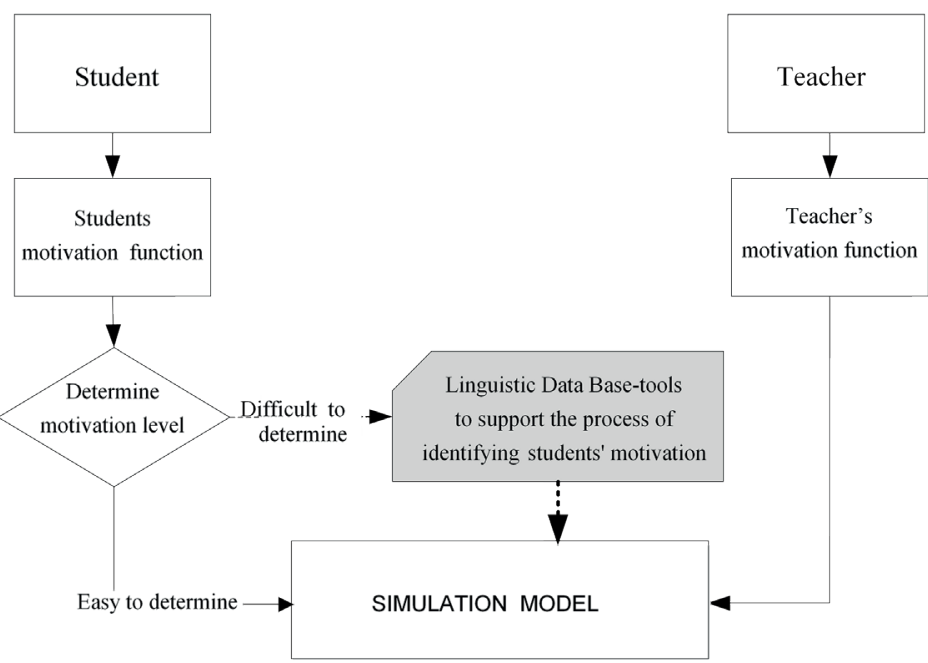

Fig. 6. Place of a tool to support the process of identifying students' motivation

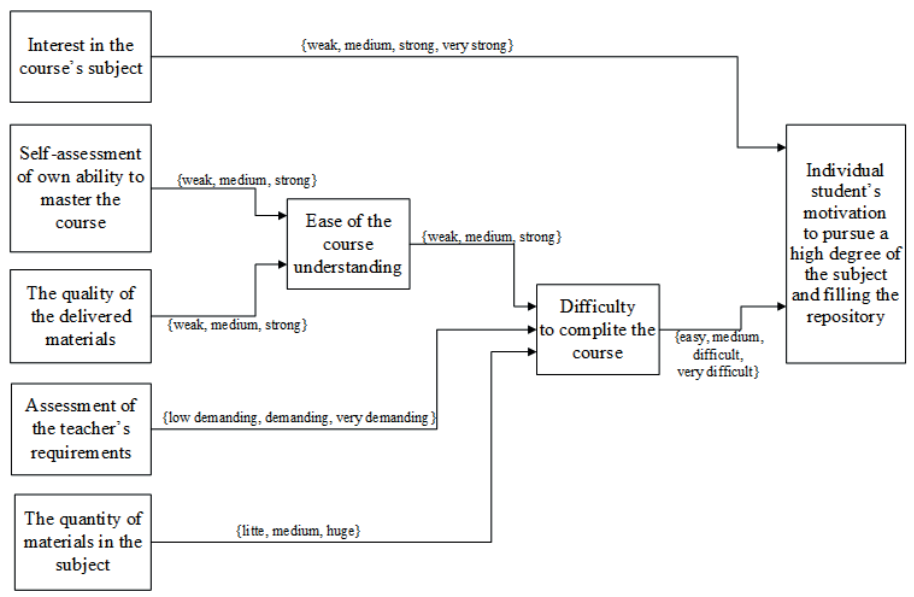

Fig. 7. Structure of linguistic data base for the purpose of identifying the student's motivation [25]
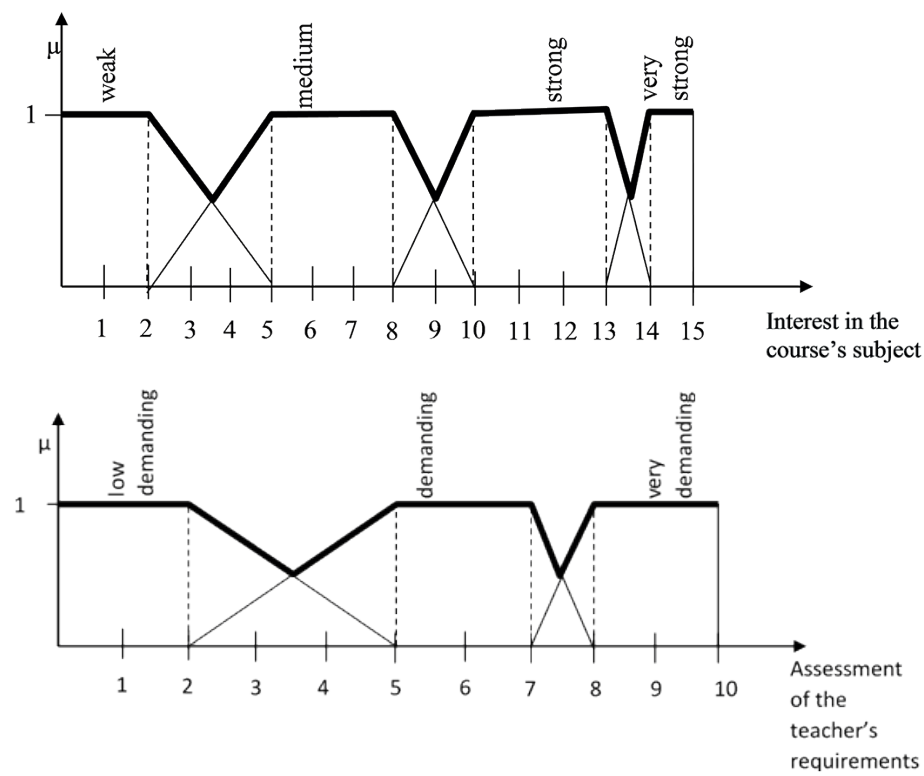

Fig. 8. Two distribution functions of the features [25] 
Table 1

Examples of conditions for conducting simulation experiment

\begin{tabular}{|c|c|c|c|}
\hline \multicolumn{2}{|c|}{$\begin{array}{l}\text { Simulation Experiment } 1 \\
\text { Determination of the number of students waiting for service by } \\
\text { a teacher at a certain interval of time, at a certain probability } \\
\text { distribution outputs, distribution of student services and the } \\
\text { estimated time of verification of tasks }\end{array}$} & \multicolumn{2}{|c|}{$\begin{array}{l}\text { Simulation Experiment } 2 \\
\text { Determination of the total time of the teacher assigned for } \\
\text { checking of tasks with a certain probability distribution of outputs, } \\
\text { distribution of students service time and the forecasted time of tasks } \\
\text { checking }\end{array}$} \\
\hline $\begin{array}{l}\text { Distribution of the arrival of } \\
\text { tasks (students): }\end{array}$ & Poisson distribution & $\begin{array}{l}\text { Distribution of the arrival of } \\
\text { tasks (students): }\end{array}$ & Poisson distribution \\
\hline $\begin{array}{l}\text { Distribution of time for student } \\
\text { services: }\end{array}$ & $\begin{array}{l}\text { Triangular: minimum }-10 \mathrm{~min} \text {, } \\
\text { most desirable }-15 \mathrm{~min}, \\
\text { maximum }-30 \mathrm{~min}\end{array}$ & $\begin{array}{l}\text { Distribution of time for student } \\
\text { services: }\end{array}$ & $\begin{array}{l}\text { Triangular: minimum }-10 \mathrm{~min} \text {, } \\
\text { most desirable }-15 \mathrm{~min}, \\
\text { maximum }-30 \mathrm{~min}\end{array}$ \\
\hline Number of service channels: & 1 & Number of service channels: & 1 \\
\hline The time interval: & 6 days & The time interval: & Indefinite \\
\hline $\begin{array}{l}\text { Time assigned for work with } \\
\text { students (checking of tasks): }\end{array}$ & $3 \mathrm{~h} / 1$ days & $\begin{array}{l}\text { Time assigned for work with } \\
\text { students (checking of tasks): }\end{array}$ & $3 \mathrm{~h} / 1$ days \\
\hline Number of students: & 55 students ( 55 complex tasks) & Number of students: & 55 students (55 complex tasks) \\
\hline $\begin{array}{l}\text { Probability of students' going } \\
\text { to one of the outputs: }\end{array}$ & $\begin{array}{l}\text { completion }-70 \% \text {, a repository } \\
-15 \% \text { correction }-15 \%\end{array}$ & $\begin{array}{l}\text { Probability of students' going to } \\
\text { one of the outputs: }\end{array}$ & $\begin{array}{l}\text { completion }-70 \%, \text { a repository } \\
-15 \% \text { correction }-15 \%\end{array}$ \\
\hline Time to correct the task (delay): & 1 day & Time to correct the task (delay): & 1 day \\
\hline \multicolumn{2}{|c|}{ Results of simulation experiment 1} & \multicolumn{2}{|c|}{ Results of simulation experiment 2} \\
\hline Name of the counter & Achieved value & Name of the counter & Achieved value \\
\hline $\begin{array}{l}\text { Teacher time spent for checking } \\
\text { all the tasks }\end{array}$ & 60 & $\begin{array}{l}\text { Teacher time spent for checking } \\
\text { all the tasks }\end{array}$ & 75 \\
\hline $\begin{array}{l}\text { Total number of tasks addressed } \\
\text { to correction }\end{array}$ & 18 & $\begin{array}{l}\text { Total number of tasks addressed } \\
\text { to correction }\end{array}$ & 20 \\
\hline $\begin{array}{l}\text { The number of tasks at the } \\
\text { beginning }\end{array}$ & 55 & $\begin{array}{l}\text { the number of tasks at the } \\
\text { beginning }\end{array}$ & 55 \\
\hline $\begin{array}{l}\text { The number of tasks at the } \\
\text { repository }\end{array}$ & 8 & $\begin{array}{l}\text { The number of tasks at the } \\
\text { repository }\end{array}$ & 9 \\
\hline Output of completed tasks & 34 & Output of completed tasks & 46 \\
\hline \multicolumn{2}{|c|}{$\begin{array}{l}\text { The number of students who at a certain time do not complete the } \\
\text { cycle of competence acquisition } 13\end{array}$} & \multicolumn{2}{|c|}{$\begin{array}{l}\text { Time interval allowed completing the cycle of students' competence } \\
\text { acquisition } 8 \text { days }\end{array}$} \\
\hline
\end{tabular}

Individual aggregation allows categorizing students within presented space of the motivation function. If each student determines proper motivation and the student are placed in the depicted space, this information may be used to estimate the initial setup of simulation e.g. forecasting of students service time (students use of the teacher) or forecasting the probability of outputs from the model for different degrees of competence development.

\subsection{Example of a simulation model for a teacher working} with group of students in the process of acquiring competence. Carrying out simulation experiments can be performed in a simulation package Arena. An example of an simulation model allows considering different values of input parameters and their impact on earnings. To determine the value of la- bour input, information about the level of student motivation can be used, which can be helpful in determining e. g. time of task execution by a student. Simulation experiments can be an indication for the teacher whether the expected strategy of working with the group of students allows for obtaining the assumed level of competence development. On the basis of the obtained results the teacher can introduce changes to the adopted strategy and check the new conditions in the simulation model. An example of such activity is presented in Table 1. For conducting experiments a queuing system model in Kendall's notation $\mathrm{M} / \mathrm{G} / 1$ was used. It was assumed that students (tasks) arrive according to Poisson's distribution (inter-arrival time distribution), and are served by one server (teacher) with triangular service time distribution [30]. 


\author{
Distribution \\ of incoming taska
}

The forecast distribution

of service time

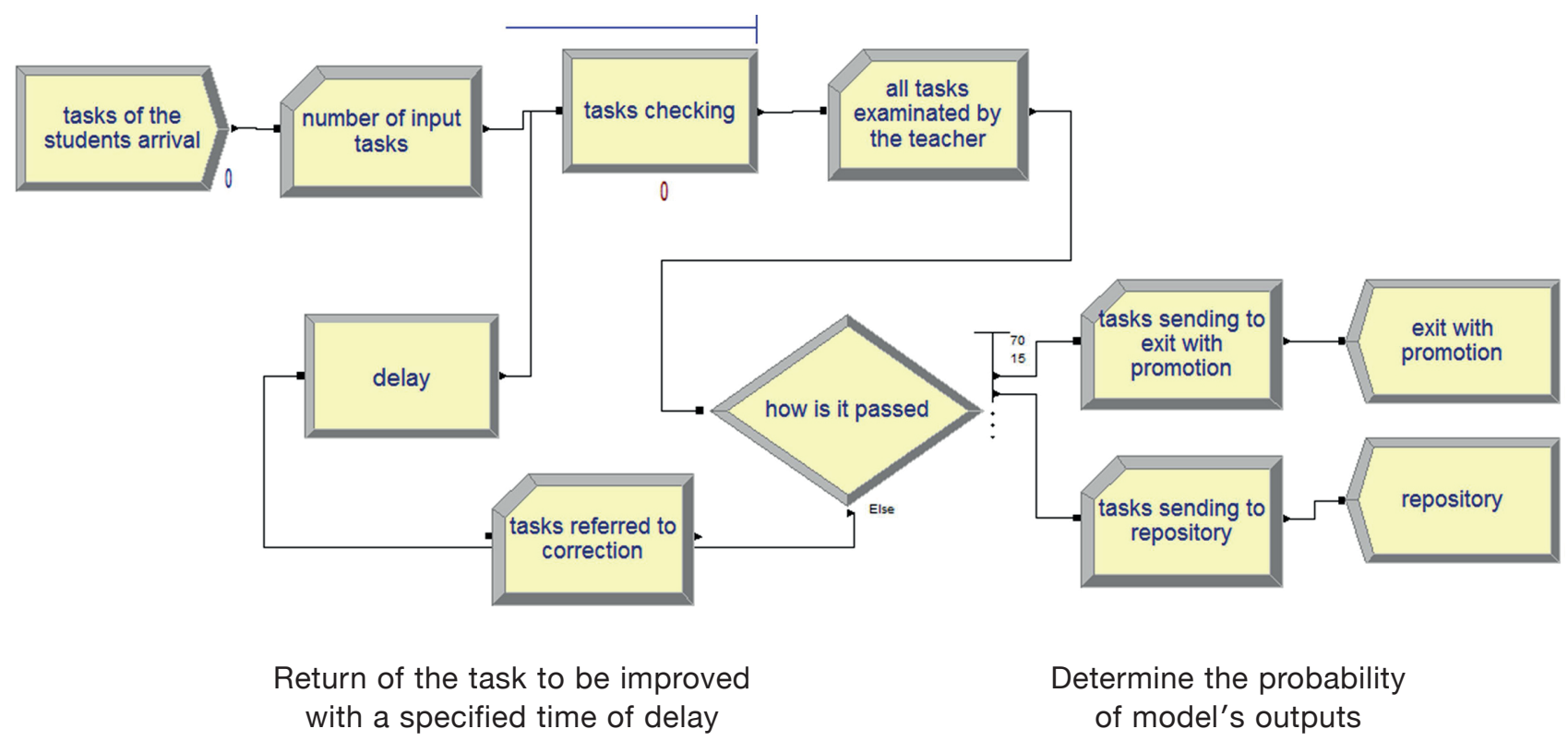

Fig. 9. An example diagram of a simulation model of the teacher's work with a group of students in the process of acquiring competence (adapted from [25])

\section{Conclusions}

Building a repository of students' knowledge can be an important motivational factor for students and for teachers. Students have the opportunity to actively work with their acquired knowledge and competences in a way where they can follow the results visually and discuss them with their peer-students and teachers. The motivation for the teachers can be an element of the learning management and a pedagogical strategy of ODL. The presented approach developed a new way of teaching and teacher's involvement, during the process the teacher observes whether the students get the relevant knowledge and competence goals. The students and the teacher can follow the process and relate to the outcome and make the necessary adjustments to the desired goals. Finally it is possible for the teacher to balance the workload with the students' results.

The motivation model includes both teacher's and students' interest in extension of the knowledge repository as they both can share and develop the repository into new functions. The measure of success in cooperation between the teacher and the students, according to the presented scenario, is the level of the repository content development in a given time. The proposed motivation model can be solved on the basis of one of the known algorithms realizing a cooperative game with dominant strategy (RDS).

To analyse the constrains of this cooperation, the simulation approach is proposed. The simulation allows to compare the expected costs that the teacher will bear considering the assumed repository development (working time) with the re- sults achieved in the didactic process (number of students with a high level of competence - participating in the repository, number of students with an average level of competence, etc.). Simulated experiments can be a useful indicators for teachers' to know whether their pedagogical strategy works for obtaining the assumed level of competence development for the students within certain amount of work and time.

\section{REFERENCES}

[1] A.W. Bates, Technology, E-learning and Distance Education, 2nd ed., Routledge Falmer, New York, 2005.

[2] O. Zawacki-Richter and T. Anderson, Online Distance Education Towards a Research Agenda, AU Press, Athabasca University, 2014.

[3] J. Larreamendy-Joerns and G. Lainhardt, "Going the distance with online education”, Review of Educational Research 76 (4), 567-605 (2006).

[4] G. Rumble and C. Latchem, "Organizational models for open and distance learning", in Policy for open and distance learning, eds. H. Perraton and H. Lentell, Routledge Falmer, London, 2004.

[5] J. Brophy, Motivating Students to Learn, 3rd ed., Routledge, New York, 2010.

[6] S. Hrastinski, "Participating in syncronous online education", Lund Studies in Informatics 6, Lund, Sweden, 2007.

[7] L. Busk Kofoed and M. Stachowicz, "Problem-based learning principles in two pedagogical models", Proceedings from ICIT conference on Information and Communication Technologies in Education, Manufacturing and Research, Saratov University of Technology, Russia, 2012. 
[8] M. Hartnett, A. St. George, and J. Dron, "Examining motivation in online distance learning environments: complex, multifaceted and situation-dependent", IRRODL Journal 12 (6), 2011.

[9] P. Różewski and O. Zaikin, "Integrated mathematical model of competence-based learning-teaching process", Bull. Pol. Ac.: Tech. 63(1), 245-259 (2015).

[10] S. Barker, Psychology, 2nd ed., Pearson Education, Boston, 2004.

[11] T. Gruber, Ontology in the Encyclopedia of Database Systems, Springer-Verlag, 2009.

[12] B. Skinner, Science and Human Behavior, Free Press, New York, 1953.

[13] e-Quality, "Quality implementation in open and distance learning in a multicultural European environment", Socrates/Minerva European Union Project, http://www.e-qualityeu.org/, 2003-2006.

[14] TenCompetence, "Building the European network for lifelong competence development", http://www.tencompetence.org, 2013.

[15] P. Różewski, E. Kusztina, R. Tadeusiewicz, and O. Zaikin, "Intelligent open learning systems: Concepts, models and algorithms", Intelligent Systems Reference Library 22, Springer-Verlag, 2011.

[16] E. Kushtina, O. Zaikin, and P. Różewski, "On the knowledge repository design and management in E-Learning", in E-Service Intelligence: Methodologies, Technologies and applications, pp. 497-517, eds. J. Lu, D. Ruan, G. Zhang, Springer-Verlag, 2006.

[17] C. Coombs, M. Dawes, and A.Twersky, Mathematical Psychology, Englewood Cliffs, New York, 1970.

[18] M. Shubik, Game Theory in the Social Sciences: Concepts and Solutions, Massachusetts, MIT Press, 1991.

[19] E. Kusztina, O. Zaikin, and R. Tadeusiewicz, "The research behavior/attitude support model in open learning systems", Bull. Pol. Ac.: Tech. 58(4), 705-711 (2010).
[20] D. Novikov, A Theory of Control in Organizations, Institute of Control Science, Moscow, 2012.

[21] J. Anderson, Cognitive Psychology and Its Implications, 5th ed., Worth Publishing, New York, 2000.

[22] B. Tuckman, "The effect of motivational scaffolding on procrastinators' distance learning outcomes", Computers \& Education 49(2), 414-422 (2007).

[23] E. Kusztina, O. Zaikin, P. Różewski, and B. Małachowski, "Cost estimation algorithm and decision model for curriculum modification in education organization", European Journal of Operational Research 197(2), 752-763 (2009).

[24] M. Gubko and D. Novikov, Game Theory in Control of Organizational Systems, Sinteg, Moscow, 2002, [in Russian].

[25] M. Malinowska, "The reference model of information system for competence development monitoring", Ph.D. Thesis, West Pomeranian University of Technology, Szczecin, Poland, 2013, [in Polish].

[26] A. Woolfolk, Educational Psychology, 9th ed., Allynard Bacon, Boston, USA, 2009.

[27] N. Guarino, "Formal ontology in information systems", Proceedings of FOIS'98, Trento, Italy, 1998.

[28] M. Malinowska, O. Zaikin, A. Zylawski, L. Reng, and L. Busk Kofoed, "Modelling the competence acquiring process in higher education institution", IFAC Conference on Manufacturing Modelling, Management and Control, Saint Petersburg, Russia, 2013.

[29] O. Zaikin, M. Malinowska, L. Busk Kofoed, and R.Tadeusiewich., "The behavioural motivation model in open distance learning", IFAC Conference on Cognitive Science, Venice, Italy, 2014.

[30] W. Kelton, R. Sadowski, and D. Sadowski, Simulation with Arena, McGraw-Hill, New York, 1997. 